\title{
Routine Depression Assessment for Patients With Coronary Artery Disease
}

\author{
- A New Standard of Care? -
}

Ingrid Connerney, $\mathrm{PhD}$

$\mathbf{T}$ he World Health Organization's Global Burden of Disease Study predicts that ischemic heart disease and depression will be the 2 leading causes of early death and disability by the year 2020. ${ }^{1}$ Although both conditions are highly prevalent, depression is more prevalent in association with medical illness. The relationship between depression and cardiac disease is both complex and bidirectional. In healthy cohorts, people with depression have an almost 2-fold riskadjusted chance for future coronary artery disease (CAD), ${ }^{2}$ whereas in patients with $\mathrm{CAD}$, the prevalence of depression (measured at the time of the coronary event) is around 20$40 \%$, and this depression is associated with significant cardiac morbidity and mortality. ${ }^{2-4}$ In a meta-analysis of 20 studies done in patients with CAD, the odds ratio (OR) for all-cause mortality in the 2 years after the initial depression assessment was 2.24 (95\% confidence interval (CI) 1.37-3.60) in depressed patients compared with patients without depression. ${ }^{5}$ Similarly, another meta-analysis of 16 cohorts of myocardial infarction (MI) patients found depression significantly associated with all-cause mortality (OR 2.38; 95\%CI 1.76-3.22; $\mathrm{P}<0.00001)$ as well as with cardiac mortality (OR 2.59; 95\%CI $1.77-3.77 ; \mathrm{P}<0.00001){ }^{3}{ }^{3}$ Studies included in both meta-analyses used either a standardized questionnaire or a clinical interview to assess depression.

\section{Article p2878}

In this issue of the Journal, Shiozaki et al report on the association of depression symptoms measured 1 year after MI with the incidence of cardiovascular events in the median 2.9-year follow-up period. ${ }^{6}$ A self-administered 20 -item questionnaire (Zung Self-Rating Depression Scale) was mailed to patients and used to assess depression within 3 months and 1 year after MI. Cardiovascular events included cardiovascular readmissions, deaths, reinfarction, coronary angioplasty or bypass. The authors found that depression measured at 1 year post MI was significantly associated with subsequent cardiovascular events for men (hazard ratio (HR) 1.67, 95\%CI 1.01-2.77, $\mathrm{P}<0.05$ ), but not for women (HR 0.97, 95\%CI 0.33-2.87, $\mathrm{P}=0.97$ ). These results were adjusted for age, hypertension, diabetes, previous MI, smoking, and hyperlipidemia. The association between depression measured 1 year post MI and adverse cardiovascular outcomes remained significant after also controlling for depression measured within 3 months of MI. Strengths of the study include the long follow-up, large sample $(n=1,587)$ of patients from 25 hospitals, and the separate analyses for men and women.

These findings raise a couple of important questions. The first relates to the assessment of depression in cardiac patients. Is the timing of assessment an important factor in establishing an association with adverse outcomes? In most studies examining the association of depression with adverse cardiac outcomes, depression was measured at the time of cardiac procedure or within 3 months of MI.,3 Shiozaki et al report that depression measured at 1 year predicted cardiovascular events after adjusting for depression measured within 3 months of MI. ${ }^{6}$ In heart failure patients, worsening of depression over a 1-year follow-up period was associated with twice the risk of death and cardiovascular hospitalization in the subsequent 5-year period. ${ }^{7}$ Similarly, Nicholson et al found in their metaanalyses that the 4 studies that assessed depression at least 2 weeks after MI found a stronger association of depression and mortality, compared with 10 studies in which the assessment was done earlier. A few additional studies found that new onset of depression predicted higher mortality compared with recurrent depression in patients post $\mathrm{MI}^{8,9}$ and post coronary artery bypass surgery. ${ }^{10}$ Connerney et al found that patients with newly-identified depression experienced more than twice the mortality over 10 years compared with patients who had never been depressed. ${ }^{10}$

In summary, a number of studies have shown that depression, measured at different times relative to a coronary event, is associated with adverse cardiac outcomes, including mortality. It now appears that depression emerging subsequent to the initial cardiac procedure or event may likewise presage adverse cardiac outcomes.

Second, how effective is screening for depression in the cardiac patient? In a recent review of the literature, Thombs et al concluded that there was no evidence that depression screening and treatment led to improved cardiac outcomes. ${ }^{11}$ However, there is evidence that treatment of depression with medication or cognitive behavioral therapy in patients with CAD is associated with improvements in depressive symptoms, ${ }^{11}$ quality of life, ${ }^{12}$ and better adherence. ${ }^{13}$ In 2008, the American Heart Association (AHA) published recommendations for routine screening of depression in patients with $\mathrm{CAD}^{14}$ that include

The opinions expressed in this article are not necessarily those of the editors or of the Japanese Circulation Society.

Received October 17, 2011; accepted October 17, 2011; released online November 12, 2011

Department of Organizational Systems and Adult Health, University of Maryland School of Nursing, Baltimore, MD, USA

Mailing address: Ingrid Connerney, PhD, Quality and Safety, University of Maryland Medical Center, 110 S. Paca Street, Suite 400, Baltimore, MD 21201, USA. E-mail: iconnerney@umm.edu

ISSN-1346-9843 doi:10.1253/circj.CJ-11-1186

All rights are reserved to the Japanese Circulation Society. For permissions, please e-mail: cj@j-circ.or.jp 
the use of a 2-step assessment protocol starting with the 2-item Patient Health Questionnaire (PHQ-2). The PHQ-2 asks the following questions: Over the past 2 weeks, how often have you been bothered by any of the following problems: (1) Little interest or pleasure in doing things, and (2) Feeling down, depressed, or hopeless. A positive response to either question should result in further assessment with either the 9-item Patient Health Questionnaire (PHQ-9) or a more comprehensive clinical evaluation. Routine screening of patients with CAD may be done in the hospital or at clinic visits, but followup should be conducted by clinicians qualified to manage depression. Routine screening without appropriate follow-up has minimal effect on the recognition of depression by clinicians or on prescription of antidepressant medication. ${ }^{15}$ Elderon et $\mathrm{al}^{16}$ evaluated the AHA-recommended 2-step screening method in a sample of 1,024 patients with CAD and reported high specificity $(91 \%)$ but low sensitivity $(52 \%)$ of the PHQ-2 followed by the PHQ-9 for a diagnosis of major depressive disorder (assessed with the computerized Diagnostic Interview Schedule for DSM-IV). However, patients who did have depression according to the screening criteria had a $41 \%$ greater risk of cardiovascular events during 6 years of followup. ${ }^{16}$ The AHA-recommended 2-step depression screen facilitates routine screening, but needs to be combined with a commitment to do further evaluation or to refer patients for further evaluation, and provision of care for the depressed patient.

In conclusion, Shiozaki et al have shown that depression emerging during the year after MI is significantly associated with subsequent cardiovascular events in a 2.9-year follow-up for male patients. ${ }^{6}$ This finding supports the need for routine and repeated screening for depression, and the need for further studies to understand the relationship between depression, treatment of depression, and adverse cardiac outcomes for male and female patients. Depression is associated with adverse cardiac outcomes through complex biological and behavioral pathways. We need to better identify strategies for identifying and treating depression in different populations and settings, and to test which interventions will most likely improve outcomes.

\section{References}

1. Murray CJ, Lopez AD. Global mortality, disability, and the contribution of risk factors: Global burden of disease study. Lancet 1997; 349: $1436-1442$.

2. Nicholson A, Kuper H, Hemingway H. Depression as an aetiologic and prognostic factor in coronary heart disease: A meta-analysis of 6362 events among 146538 participants in 54 observational studies.
Eur Heart J 2006; 27: 2763-2774.

3. van Melle JP, de Jonge P, Spijkerman TA, Tijssen JG, Ormel J, van Veldhuisen DJ, et al. Prognostic association of depression following myocardial infarction with mortality and cardiovascular events: A meta-analysis. Psychosom Med 2004; 66: 814-822.

4. Suzuki T, Shiga T, Kuwahara K, Kobayashi S, Suzuki S, Nishimura $\mathrm{K}$, et al. Depression and outcomes in hospitalized japanese patients with cardiovascular disease. Circ J 2011; 75: 2465-2473.

5. Barth J, Schumacher M, Herrmann-Lingen C. Depression as a risk factor for mortality in patients with coronary heart disease: A metaanalysis. Psychosom Med 2004; 66: 802-813.

6. Shiozaki M, Iso H, Ohira T, Nakatani D, Shimizu M, Sakata Y, et al. Longitudinal risk of cardiovascular events in relation to depression symptoms after discharge among survivors of myocardial infarction: Osaka Acute Coronary Insufficiency Study (OACIS). Circ J 2011; 75: $2878-2884$.

7. Sherwood A, Blumenthal JA, Hinderliter AL, Koch GG, Adams KF $\mathrm{Jr}$, Dupree CS, et al. Worsening depressive symptoms are associated with adverse clinical outcomes in patients with heart failure. $J \mathrm{Am}$ Coll Cardiol 2011; 57: 418-423.

8. Carney RM, Freedland KE, Steinmeyer B, Blumenthal JA, de Jonge $\mathrm{P}$, Davidson KW, et al. History of depression and survival after acute myocardial infarction. Psychosom Med 2009; 71: 253-259.

9. Dickens C, McGowan L, Percival C, Tomenson B, Cotter L, Heagerty A, et al. New onset depression following myocardial infarction predicts cardiac mortality. Psychosom Med 2008; 70: 450-455.

10. Connerney I, Sloan RP, Shapiro PA, Bagiella E, Seckman C. Depression is associated with increased mortality 10 years after coronary artery bypass surgery. Psychosom Med 2010; 72: 874-881.

11. Thombs BD, de Jonge P, Coyne JC, Whooley MA, Frasure-Smith N, Mitchell AJ, et al. Depression screening and patient outcomes in cardiovascular care: A systematic review. JAMA 2008; 300: 2161 2171.

12. Rollman BL, Belnap BH, LeMenager MS, Mazumdar S, Houck PR, Counihan PJ, et al. Telephone-delivered collaborative care for treating post-cabg depression: A randomized controlled trial. JAMA 2009; 302: 2095-2103.

13. Rieckmann N, Gerin W, Kronish IM, Burg MM, Chaplin WF, Kong $\mathrm{G}$, et al. Course of depressive symptoms and medication adherence after acute coronary syndromes: An electronic medication monitoring study. J Am Coll Cardiol 2006; 48: 2218-2222.

14. Lichtman JH, Bigger JT Jr, Blumenthal JA, Frasure-Smith N, Kaufmann PG, Lesperance F, et al. Depression and coronary heart disease: Recommendations for screening, referral, and treatment: A science advisory from the American Heart Association Prevention Committee of the Council on Cardiovascular Nursing, Council on Clinical Cardiology, Council on Epidemiology and Prevention, and interdisciplinary council on quality of care and outcomes research: Endorsed by the American Psychiatric Association. Circulation 2008; 118: $1768-1775$.

15. Gilbody S, Sheldon T, House A. Screening and case-finding instruments for depression: A meta-analysis. Can Med Assoc J 2008; 178: 997-1003.

16. Elderon L, Smolderen KG, Na B, Whooley MA. Accuracy and prognostic value of american heart association-recommended depression screening in patients with coronary heart disease: Data from the heart and soul study. Circ Cardiovasc Qual Outcomes 2011; 4: 533-540. 